\title{
Nucleolin Promotes Heat Shock-Associated Translation of VEGF-D to Promote Tumor Lymphangiogenesis
}

\author{
Florent Morfoisse ${ }^{1}$, Florence Tatin 1 , Fransky Hantelys ${ }^{1}$, Aurelien Adoue', \\ Anne-Catherine Helfer ${ }^{2}$, Stephanie Cassant-Sourdy ${ }^{3}$, Francoise Pujol', \\ Anne Gomez-Brouchet ${ }^{4,5}$, Laetitia Ligat ${ }^{6}$, Frederic Lopez ${ }^{6}$, Stephane Pyronnet ${ }^{3}$, \\ Jose Courty ${ }^{7}$, Julie Guillermet-Guibert ${ }^{3}$, Stefano Marzi ${ }^{2}$, Robert J. Schneider ${ }^{8}$, \\ Anne-Catherine Prats ${ }^{1}$, and Barbara H. Garmy-Susini ${ }^{1}$
}

\section{Abstract}

The vascular endothelial growth factor VEGF-D promotes metastasis by inducing lymphangiogenesis and dilatation of the lymphatic vasculature, facilitating tumor cell extravasion. Here we report a novel level of control for VEGF-D expression at the level of protein translation. In human tumor cells, VEGF-D colocalized with eIF4GI and 4E-BP1, which can program increased initiation at IRES motifs on mRNA by the translational initiation complex. In murine tumors, the steady-state level of VEGF-D protein was increased despite the overexpression and dephosphorylation of $4 \mathrm{E}-\mathrm{BP} 1$, which downregulates protein synthesis, suggesting the presence of an internal ribosome entry site (IRES) in the $5^{\prime}$ UTR of VEGF-D mRNA. We found that nucleolin, a nucleolar protein involved in ribosomal maturation, bound directly to the $5^{\prime} \mathrm{UTR}$ of VEGF-D mRNA, thereby improving its translation following heat shock stress via IRES activation. Nucleolin blockade by RNAi-mediated silencing or pharmacologic inhibition reduced VEGF-D translation along with a subsequent constriction of lymphatic vessels in tumors. Our results identify nucleolin as a key regulator of VEGF-D expression, deepening understanding of lymphangiogenesis control during tumor formation. Cancer Res; 76(15); 4394-405. (2016 AACR.

\section{Introduction}

Lymphatic vessels encircle tumors and enhance metastasis by improving the capillary high permeability and the collecting vessels' dilatation (1). Nonetheless, very little is known regarding the molecular mechanisms governing cancer invasion into the lymphatic system.

VEGF-C and VEGF-D are the chief inducers of lymphangiogenesis (2). Their activity is regulated by protein processing that occurs mainly in the extracellular environment to generate peptides with high affinity for their receptor, VEGFR-3 $(3,4)$. Our group recently identified regulation of VEGF-C at the translational initiation step induced by hypoxic stress (5). The stress-induced VEGF production in pathologic conditions has

${ }^{1}$ UMR 1048-112MC, Université de Toulouse, Inserm, UPS, Toulouse, France. ${ }^{2}$ IBMC-CNRS, Université de Strasbourg, Strasbourg, France. ${ }^{3}$ UMR 1037-CRCT, Inserm, UPS, Toulouse, France. ${ }^{4}$ UMR 5089-IPBS, CNRS, UPS, Toulouse, France. ${ }^{5}$ Department of Pathology, IUCT-Oncopole, Toulouse, France. ${ }^{6}$ Pôle Technologique du CRCT - INSERMUMR1037, Toulouse, France. ${ }^{7}$ Laboratoire CRRET Laboratory, Université Paris EST Créteil, Créteil, France. ${ }^{8}$ NYU School of Medicine, New York, New York.

Note: Supplementary data for this article are available at Cancer Research Online (http://cancerres.aacrjournals.org/)

Corresponding Author: Barbara H. Garmy-Susini, INSERM, 1 av J. poulhes Eq15, BP84225, Toulouse 31432, France. Phone: 3356-1312-24087; Fax: 335-6132-3841; E-mail: barbara.garmy-susini@inserm.fr

doi: 10.1158/0008-5472.CAN-15-3140

(C)2016 American Association for Cancer Research. been largely described in the literature $(6,7)$. In this study, we sought to identify whether VEGF-D activity responds to cellular stress.

VEGF-D was first described to promote tumor metastasis through the lymphatic system $(8,9)$. This observation was extended to many solid tumors such as pancreatic cancer and endometrial cancer $(10,11)$. More recently, Karnezis and colleagues have demonstrated that the prometastatic effect of VEGF-D was associated with a lymphatic collecting vessel dilatation by regulating the prostaglandin pathway (1). The effect of VEGF-D on vessel enlargement was also observed in dermal initial lymphatics (12). Here, we found an original mechanism underlying regulation of VEGF-D translation that is induced by increased temperature.

Translational control plays a critical role in the regulation of gene expression during tumor development (13). In fact, the majority of cellular stresses lead to strong inhibition of mRNA translation by the classical cap-dependent scanning mechanism $(5,14)$. Several mRNAs, however, are translated by an eIF4Eindependent mechanism, mediated by internal ribosome entry site (IRES) that are mRNA structures located in IRESs were previously described for VEGF-A and VEGF-C mRNA $(15,16)$. Here, we demonstrated that the $5^{\prime}$ UTR of VEGF-D mRNA harbors an IRES trans-acting factor, which drives VEGF-D translation under heat shock stress.

IRES-dependent translation initiation is controlled by IRES trans-acting factors (ITAF), which participate in the recruitment of the small ribosome subunit (17). ITAFs seemingly stabilize the IRES active conformation (18) to allow efficient expression of key regulators in tumor growth and spreading (16). The activity of 
ITAFs is dependent on their subcellular localization. They are nuclear proteins that are exported to the cytoplasm to participate in mRNA translation initiation (19). ITAFs bind the mRNA $5^{\prime}$ untranslated region to recruit the ribosome, thereby promoting protein synthesis under stress conditions. Here, we found that nucleolin, a multifunctional nucleolar protein involved in ribosome maturation, is an ITAF of the VEGF-D mRNA. Specifically, our data showed that cytoplasmic accumulation of nucleolin in cells enduring heat shock improved VEGF-D mRNA translation by binding of ITAF to the VEGF-D $5^{\prime}$ UTR.

Nucleolin was first described to be an ITAF for viral $5^{\prime}$ UTR mRNAs such as rhinovirus (20). Recently, nucleolin was shown to participate in IRES-dependent translation of cellular mRNAs. It associated with hnRNP proteins to promote translation of long interspersed element one (LINE-1; ref. 21). Moreover, recent reports confirmed the ITAF activity of nucleolin during tumorigenesis and demonstrated that it is a key regulator of specificity protein $1(\mathrm{Sp} 1)$ protein accumulation via induction of its IRESdependent translation initiation (22).

In the current study, we demonstrate a link between the translational control of VEGF-D expression and lymphatic dilatation. We show that RNA-binding protein nucleolin specifically and directly binds to the $5^{\prime}$ UTR of VEGF-D and functions to induce VEGF-D mRNA translation in cells. Our results advocate that nucleolin contributes to the maintenance of lymphatic vessel plasticity under heat shock stress conditions by controlling VEGFD expression.

Of interest, inhibition of nucleolin synthesis by NSAIDs specifically repressed VEGF-D translation, suggesting a putative protein synthesis control using NSAIDs that could interfere with a physiologic function such as lymphatic dilatation.

Altogether, our results suggest that nucleolin contributes to the maintenance of lymphatic functioning network by controlling the expression of VEGF-D.

\section{Materials and Methods}

Tissue specimens

In total, 15 primary human breast cancer specimens and their associated lymph nodes were collected. Samples were obtained from archival paraffin blocks of breast cancer from patients treated at the Rangueil hospital (Toulouse, France) between 2002 and 2008. Samples were selected as coded specimens under a protocol approved by the INSERM Institutional Review Board (DC-2008-463) and Research State Department (Ministère de la recherche, ARS, CPP2, authorization AC-2008-820) and included tumor specimens identified as invasive ductal carcinoma. Each series included as controls normal breast tissue from the same patient.

\section{Tumor studies}

Animal experiments were conducted in accordance with recommendations of the European Convention for the Protection of Vertebrate Animals used for experimentation. All animal experiments were performed according to the INSERM Institutional Animal Care and Use Committee guidelines for laboratory animals' husbandry and have been approved by the local branch INSERM Rangueil-Purpan of the Midi-Pyrénées ethics committee (protocol $\mathrm{n}^{\circ}$ 091037615).

In total, $5 \times 10^{5}$ cells of murine Lewis Lung Carcinoma (LLC1; ATCC CRL-1642; obtained in 2011) and human pancreatic ade- nocarcinoma (Capan-1, ATCC HTB79; obtained in 2009) cell lines were injected subcutaneously into wild type (WT, $n=8-10$ ) mice on a C57Bl6 or NMRI Nu/Nu background, respectively $(n=$ 8-10). Animals were sacrificed 2 or 3 weeks later when tumors and inguinal lymph nodes were excised and embedded into optimal cutting temperature (OCT) compound (Tissue-Tek; Sakura Finetek). To study the orthotopic model of breast carcinoma, $5 \times 10^{4}$ syngeneic Balb/c 4T1 and 67NR (ATCC CRL-2539, obtained in 2007) cells were injected into Balb/c the fourth mammary fat pad $(n=8-10)$. Animals were sacrificed 1 or 2 weeks later when tumor and inguinal lymph nodes were excised and embedded into OCT compound.

\section{Bicistronic lentivector construction and transduction}

The cDNAs coding human VEGF-D 5'UTR and EMCV 5'UTR were subcloned between the Renilla (LucR) and firefly (LucF) genes under the control of the CMV promoter into the lentivector pTRIP-DU3-CMV-MCS as described previously (5). Bicistronic lentivectors were produced using the tri-transfection procedure using the plasmids pLvPack and pLvVSVg (Sigma-Aldrich), and were evaluated for their ability to transduce the cell lines as described previously (5).

\section{Reporter gene assay}

To obtain stable vector expression in cells, the bicistronic cassette with the VEGFD $5^{\prime}$ UTRs between the two luciferase genes was introduced into lentivectors. Bicistronic lentivectors with the viral EMCV IRES and the hairpin were used as negative and positive controls. The principle of the bicistronic vector is that the first cistron, Renilla luciferase (LucR), is translated by the capdependent mechanism, whereas the second cistron, firefly luciferase (LucF), is translated under the control of the IRES. In vitro or ex vivo luciferase assays were performed on lysed cells or tissues as described previously (5).

\section{Reagents}

Rat anti-mouse VEGFD (SC101585) was from Santa Cruz Biotechnology (TebuBio). Rabbit-anti human 4E-BP1 (9644) was from Ozyme. Rabbit anti-mouse - 1 antibody (RDI-103PA50) was from Research Diagnostics Incorporated. Rat anti-mouse CD31 (MEC 13.3) was from BD Biosciences. Goat anti-PAN cytokeratin, donkey anti-rabbit, and rat IgGs conjugated with Dylights Fluors 488, 568 were from TebuBio. Anti-podoplanin was from Santa Cruz Biotechnology. Anti-luciferase Firefly was from Promega. Hypoxyprobe was from Euromedex. Anti-GAPDH was from Sigma Aldrich.

\section{Immunohistochemistry}

Tumors and lymph nodes were embedded into OCT compound and $5-\mu \mathrm{m}$ tissue sections were immunostained with specific antibodies. The mean number of lymphatic vessels $( \pm$ SEM for each treatment group) were quantified in 5-10 microscopic fields per cryosection using automated pixel density determination. The vessel diameters were quantified using 5 measures per vessel as described in Supplementary Fig. S1. In total, 3 sections/ tumor were analyzed (8-10 tumors per group), 5 microscopic fields/section leading to 100-150 fields/condition. The mean number of mice with lymph node metastases was determined by immunostaining with $10 \mu \mathrm{g} / \mathrm{mL}$ of anti-pancytokeratin and quantified in 5-10 microscopic fields per cryosection using 
automated pixel density determination as the mean number of pixels \pm SEM for each group.

\section{Quantitative real-time RT-PCR}

Total cellular RNA was isolated from mouse 4T1, 67NR, Capan1 , and LLC tumors using a tissue lyser (Ultrathurax) in TRIzol solution as described previously (5).

Primers. The following primers were used: LucF forward (F): $5^{\prime}$ TCCTATGATTATGTCCGGTTATGTAAA-3'; LucF reverse (R): $5^{\prime}$ TGTAGCCATCCATCCTTGTCAA- ${ }^{\prime}$; LucR (F): $5^{\prime}$ - ATGGGCAAATCAGGCAAA- ${ }^{\prime}$; LucR (R): 5' - CGCAATATCTTCTTCAATATCAGG3'; VEGF-D (F): 5' - CCTATTGACATGCTGTGGGAT-3'; VEGF-D (R): 5'-GTGGGTTCCTGGAGGTAAGAG-3'

\section{siRNA and cell transfection}

A pool of siRNAs synthesized by Dharmacon with the following sequences: siRNA-1: 5'-GCAAAUUCCUAUACAUCUA-3', siRNA-2: $5^{\prime}$-UGUCAGAGGUCCAGUUUAA-3' ${ }^{\prime}$ siRNA-3: 5' $^{\prime}$-UGGCAAACCUAAAGGGUAU-3', siRNA-4: 5'-UGGGAAAAGUAAAGGGAUU-3' were used. Nontargeting siRNA (siGENOME NonTargeting Smartpool; Dharmacon) was used as control. To examine the effect of the siRNAs on nucleolin protein expression, 4T1 cells were plated onto 6-well plates in antibiotic-free RPMI1640 medium supplemented with FBS $(10 \%)$ before being transfected with $20 \mathrm{nmol} / \mathrm{L}$ siRNA as described previously (5). Vehicle control and nontargeting siRNA were applied to cell culture replicates. Cells were incubated for 1 day before changing the culture medium and incubating them for 72 hours before the 30-minute heat shock. Efficacy of downregulation was analyzed by immunoblotting

\section{N6L inhibitor treatment}

N6L, a synthetic ligand of nucleolin that exerts antitumor activity in mouse xenograft model (23), was provided by J. Courty's laboratory (Laboratoire CRRET Laboratory, Université Paris EST Créteil, Créteil, France). Stock solution of N6L ( $2 \mathrm{mmol} / \mathrm{L})$ was diluted in mannitol to a final concentration of $50 \mu \mathrm{mol} / \mathrm{L}$. Heat shock was applied for 30 minutes at $42^{\circ} \mathrm{C}$.

\section{In vitro stress-induced IRES activity}

Stress stimulation assays were performed in vitro on 4T1-transduced cells. Reticulum stress was promoted using $12 \mathrm{nmol} / \mathrm{L}$ dithiothreitol (DTT; Sigma-Aldrich) during 4 and 8 hours. Deprivation stress was performed in RPMI without serum during 8 hours at $37^{\circ} \mathrm{C}$. Inflammatory stress was performed in the presence of $1 \mu \mathrm{g} / \mathrm{mL}$ lipopolysaccharid (LPS; Sigma-Aldrich Chemie $\mathrm{GmbH}$ ) during 4 and 8 hours. Heat shock was applied during $5,10,20$, and 30 minutes at $37^{\circ} \mathrm{C}$.

\section{In vivo sc-236 treatment}

NSAID treatment was performed by injecting $1 \mu \mathrm{g}$ of anti-COX2 inhibitor sc-236 (Sigma-Aldrich Chimie GmbH) every 2 days during 12 days. Tumor-bearing mice were sacrificed after 2 weeks.

RNA structure determination in solution chemical and enzymatic probing

RNA preparation, RNA structure probing, and RNA primer extension analysis were performed as described previously (5).
Primers. The following primer sequences were used:

VEGF-D_3: ATTCCCCATTCTCCATACATTTTGAATATTTTAAATGTCTACCG

VEGF-D_4: TAATACGACTCACTATAGGAAGATATGACCACCTCC

$$
\text { VEGF-D_5: GAATATTTTAAATGTCTACCG }
$$

\section{BIA-MS assays}

Biomolecular analysis coupled to mass spectrometry (BIA-MS) was performed on a BIAcore T200 optical biosensor instrument (GE Healthcare). Immobilization of biotinylated VEGF-D and EMCV IRES RNAs was performed on a streptavidin-coated (SA) sensorchip in HBS-EP buffer ( $10 \mathrm{mmol} / \mathrm{L}$ HEPES, pH 7.4, 150 $\mathrm{mmol} / \mathrm{L} \mathrm{NaCl}, 3 \mathrm{mmol} / \mathrm{L}$ EDTA, $0.005 \%$ surfactant P20; GE Healthcare). All immobilization steps were performed at a flow rate of $2 \mu \mathrm{L} /$ minute with a final concentration of $100 \mu \mathrm{g} / \mathrm{mL}$. Total amount of immobilized VEGF-D and EMCV IRES RNAs was 552 RU and $650 \mathrm{RU}$, respectively.

Binding analyses were performed with cell protein extracts at $100 \mu \mathrm{g} / \mathrm{mL}$ over the immobilized VEGF-D and EMCV IRES RNA surface at $37^{\circ} \mathrm{C}$ and $42^{\circ} \mathrm{C}$ for 7 minutes at a flow rate of $30 \mu \mathrm{L} /$ minute. The channel ( $\mathrm{Fc} 1)$ was used as a reference surface for nonspecific binding measurements. The recovery wizard was used to recover selected proteins from cell protein extracts at $37^{\circ} \mathrm{C}$ and $42^{\circ} \mathrm{C}$. This step was carried out with $0.1 \%$ SDS. Five recovery procedures were performed to get enough amounts of proteins for MS identification. LC/MS-MS analyses were performed on Bruker Amazon ETD mass spectrometer.

Polysome profiling. $4 \mathrm{~T} 1$ cell line were incubated with cycloheximide $(100 \mu \mathrm{g} / \mathrm{mL}) 15$ minutes at $37^{\circ} \mathrm{Cbefore}$ preparing extracts in hypotonic lysis buffer ( $5 \mathrm{mmol} / \mathrm{L}$ Tris-HCl, pH7.5; $2.5 \mathrm{mmol} / \mathrm{L}$ $\mathrm{MgCl} 2 ; 1.5 \mathrm{mmol} / \mathrm{L} \mathrm{KCl})$. Cell extracts were layered onto $10 \%-$ $50 \%$ sucrose gradient and sedimented via centrifugation at 39,000 rpm for 2 hours at $4^{\circ} \mathrm{C}$ in a Beckman ultracentrifuge. Fractions were collected ( 24 fractions of 12 drops each) using a Foxy JR ISCO collector and UV optical unit type 11.

\section{Statistical analysis}

All statistical analyses were performed using a two-tailed Student $t$ test or one-way ANOVA. All experiments were performed three times, with one exception, where the incidence of metastasis is reported as the average \pm SEM of three separate animal experiments. All data presented are from a single representative experiment.

\section{Results}

VEGF-D synthesis is modulated by a cap-independent initiation of mRNA translation

VEGF-D level was examined in invasive ductal breast carcinoma biopsies and compared with normal breast epithelium (Fig. 1A). VEGF-D is overexpressed in breast tumors and is associated with an upregulation of eIF4GI and 4E-BP1 expressions, suggesting a cap-independent VEGF-D synthesis.

To study the expression of VEGF-D, we performed RT-qPCR and Western blot analysis showing that VEGF-D is ubiquitously expressed in organs containing lymphatic vessels (lymph nodes, mammary gland, etc.), whereas no VEGF-D was found in organs containing no (brain) or low level (muscle) of lymphatic vessels (Supplementary Fig. S2). 
A
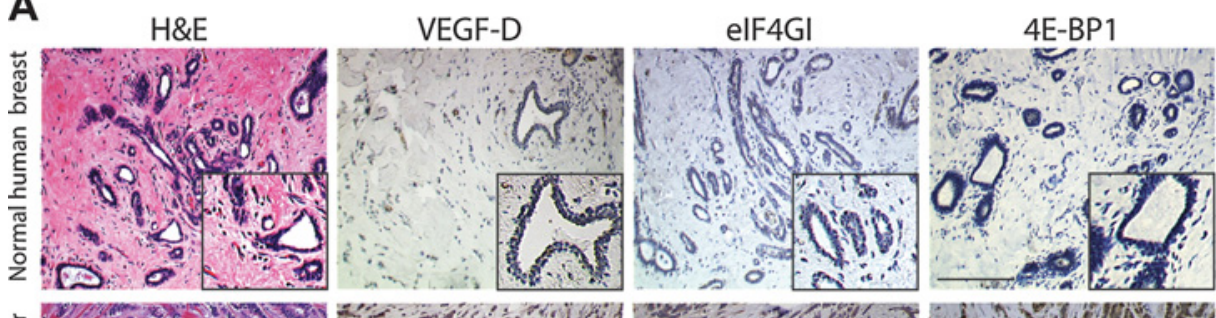

Figure 1.

VEGF-D overexpression correlates with the upregulation of elF4GI and $4 \mathrm{E}-\mathrm{BP} 1$. A, immunohistochemical staining of representative breast cancer tumors $(n=15)$ and normal breast epithelium $(n=15)$ for VEGF-D, elF4GI, and 4E-BP1. Scale bar, $100 \mu \mathrm{m}$. B, quantitative RTPCR for breast, lung, and pancreatic tumors (CA) compared with normal tissue (NL; *, $P<0.001)$. C-E, immunoblot analysis of VEGF-D and $4 \mathrm{E}-\mathrm{BP} 1$ in mouse breast, lung, and pancreatic tumors. D, quantification by densitometry of VEGF-D signal normalized to GAPDH $(*, P<0.01$ ). E, quantification by densitometry of dephosphorylated 4E-BP1 normalized to GAPDH $(*, P<0.001)$. n.s. nonsignificant.

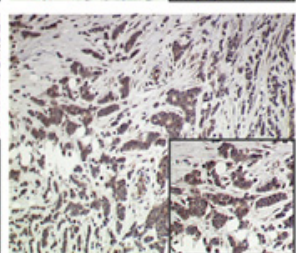

C

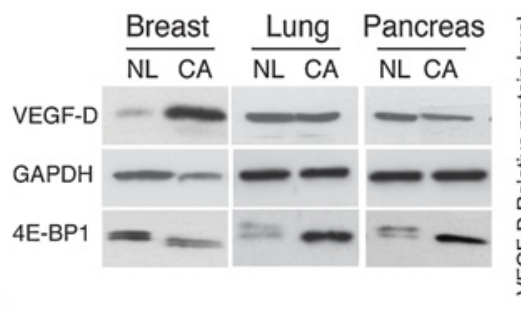

D
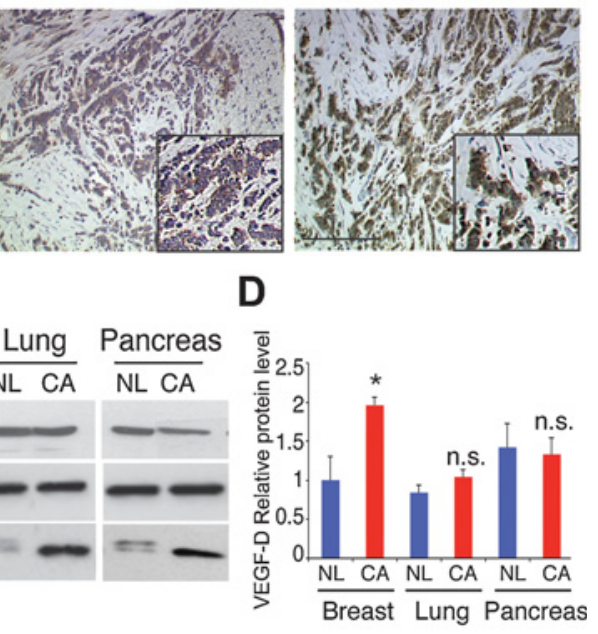

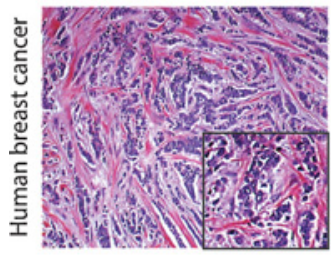

B

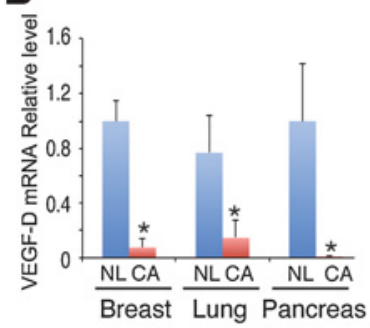

E

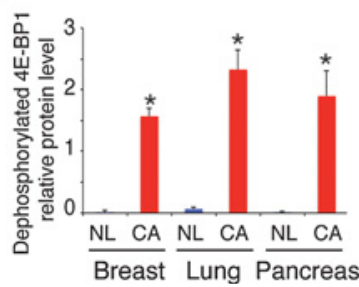


A

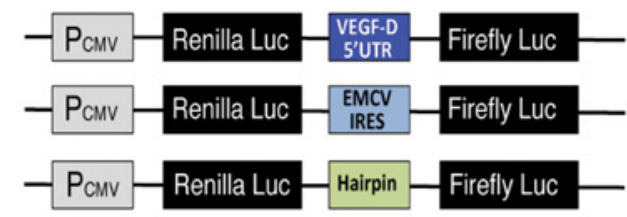

B

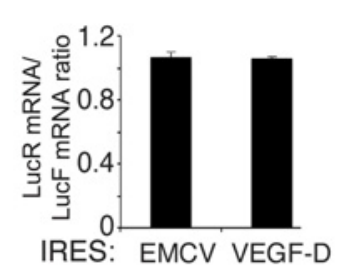

C

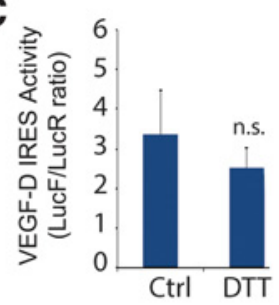

D

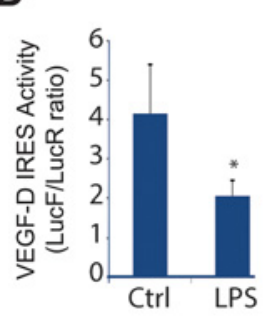

E

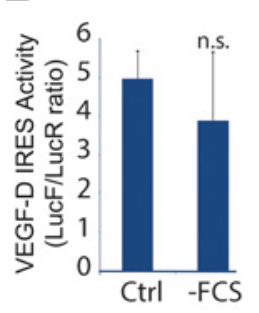

F

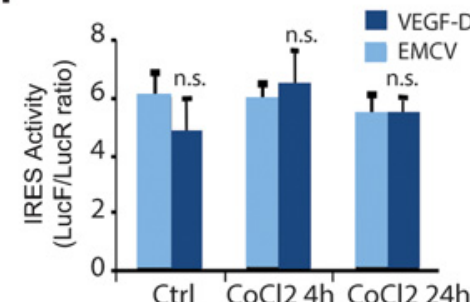

G

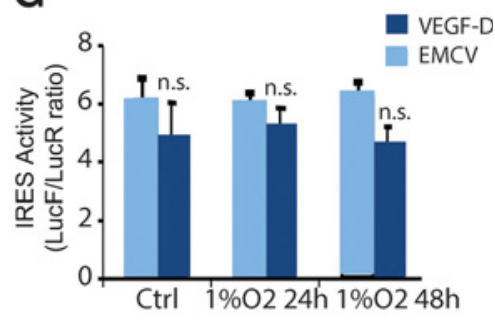

H

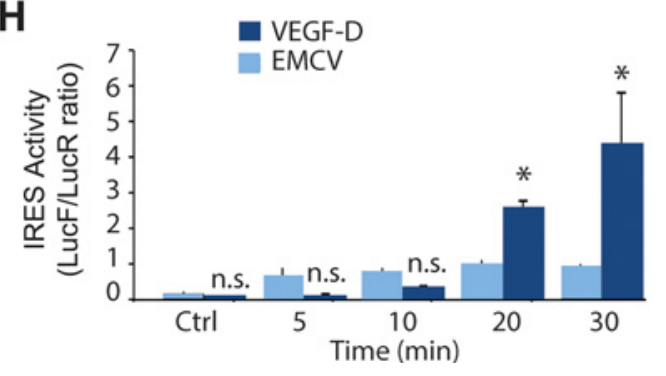

I

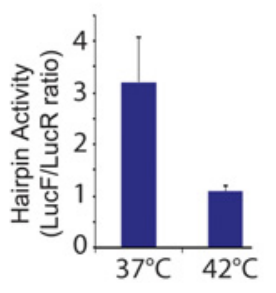

Figure 2.

VEGF-D mRNA contains an IRES element. A, schematics of the bicistronic expression cassettes subcloned into lentivectors. B, ratio of quantitative RT-PCR relative values for LucR versus LucF, separated by VEGF-D 5'UTR. C-G, in vitro VEGF-D IRES activity in 4T1 cell lines submitted to DTT-induced endoplasmic reticulum stress (C), lipopolysaccharide (LPS) inflammatory stress (D), nutriment deprivation (-FCS) stress (E), and hypoxic stresses (F and $\mathbf{G})$. $\mathbf{H}$ and $\mathbf{I}$, in vitro VEGF-D and EMCV IRES (H) activities in $4 \mathrm{T1}$ cell lines submitted to heat shock stress (I). In vitro hairpin activity in $4 \mathrm{T1}$ cell lines submitted to heat shock stress. n.s., nonsignificant.

increasing lymph flow through vessel dilation (28). Vessel dilatation is mainly observed during inflammation and is promoted by an activation of the endothelial prostaglandin pathways (29). Therefore, we submitted 4T1 transduced cell lines to physiologic stresses associated with a local vasodilatation to identify which stimulus is associated with IRES activation (Fig. 2C-I). VEGF-D IRES activity was not affected by endoplasmic reticulum stress (Fig. 2C), lipopolysaccharides (Fig. 2D), serum deprivation (Fig. 2E), or hypoxia (Fig. 2F and G). In contrast, VEGF-D IRES activity was significantly activated in vitro after 20-minute heat shock (Fig. 2H), whereas no activation was found for EMCV control IRES (Fig. 2H) or hairpin (Fig. 2I).

VEGF-D synthesis promotes lymphatic vessel dilatation and metastasis

The role of overexpressed VEGF-D was examined in mice breast tumor models. We compared lymphatic-mediated metastasis in $4 \mathrm{~T} 1$ tumors to orthotopic syngeneic 67NR low metastatic breast tumors. Despite similar level of VEGF-D mRNA in $4 \mathrm{~T} 1$ and $67 \mathrm{NR}$ cell lines (Fig. 3A), we found that 67 NR poorly expressed VEGF-D compared with 4T1 (Fig. 3B and C). Surprisingly, this difference in VEGF-D expression had no effect on tumor growth (Fig. 3D). To investigate the role of VEGF-D in breast tumors lymphatic vessels, we performed immunostaining using antibodies directed against lymphatic vessel endothelial receptor (LYVE-1; ref. 30) and podoplanin (Fig. 3E and Supplementary Fig. S3; ref. 31).

In these models, VEGF-D expression has no effect on tumor lymphangiogenesis (Fig. 3E and F). In parallel, we found that the tumor expressing a high level of VEGF-D (4T1) exhibited dilated tumor lymphatic vessels compared to tumor with low level of VEGF-D (67NR; Fig. 3G and H). As expected, the lymphatic vessel dilatation is associated with an increase of tumor metastasis (Fig. 3I and J), but has no effect on draining lymph nodes lymphangiogenesis (Supplementary Fig. S4).

To identify in vivo VEGF-D IRES activity, bicistronic lentivector-transduced $4 \mathrm{~T} 1$ and $67 \mathrm{NR}$ cell lines were injected in mice mammary fat pad (Fig. 3K-N). IRES activity in tumors was observed using immunodetection of firefly luciferase and quantified by measuring luciferase activities after 7 and 14 days (Fig. $3 \mathrm{~K}-\mathrm{N}$ and Supplementary Fig. S4). We checked that the transduction of the reporter genes did not affect tumor growth (Supplementary Fig. S4). Interestingly, VEGF-D IRES activity strongly increased in 4T1 tumors (Fig. 3K) compared with EMCV IRES (Fig. 3L), but not in 67NR tumors (Fig. 3M), which exhibit low VEGF-D protein levels. As expected, the EMCV viral IRES, which is not involved in angiogenesis or lymphangiogenesis stimulation, was poorly (4T1) or not (67NR) activated during tumorigenesis (Fig. 2L and N). 
A

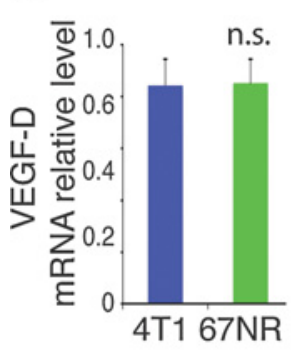

B

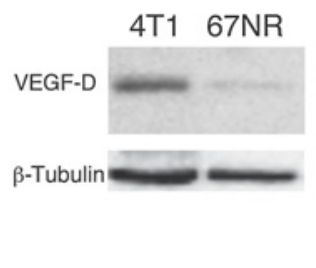

C

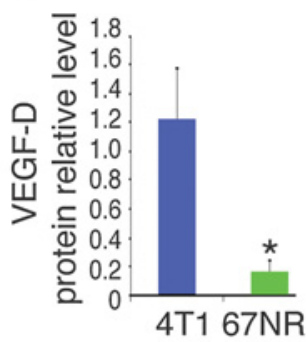

D

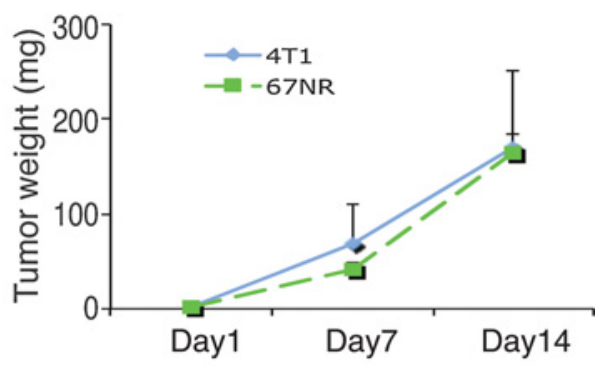

F

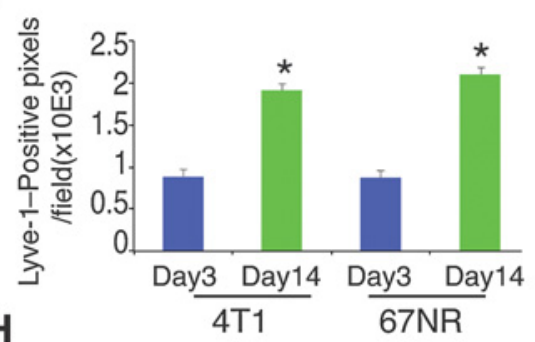

G
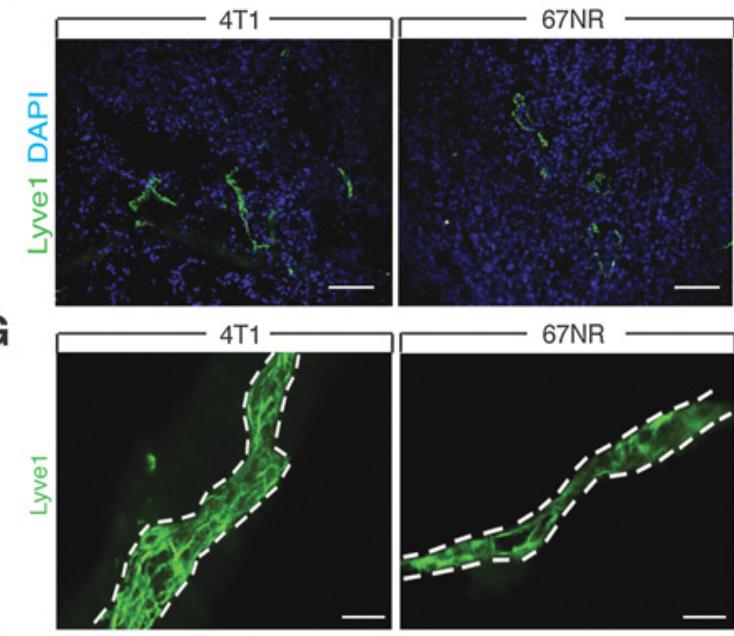

I
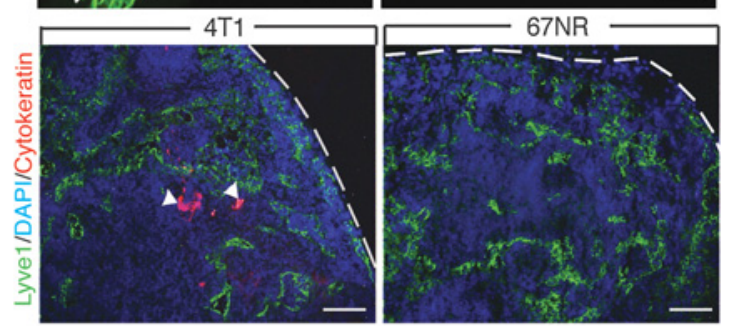

K

4T1

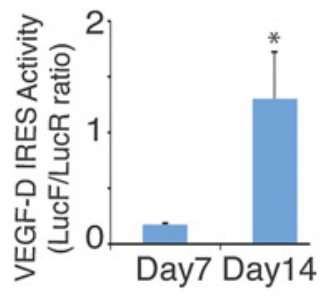

L

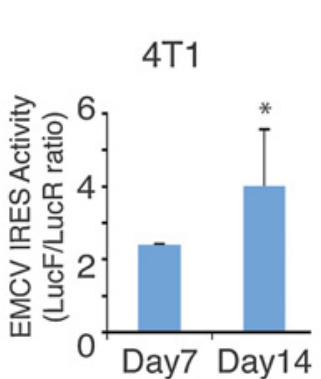

$\mathrm{H}$

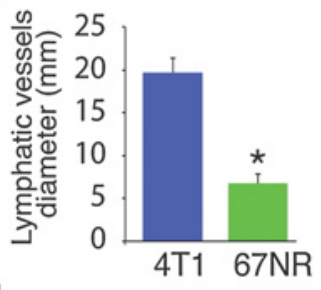

J

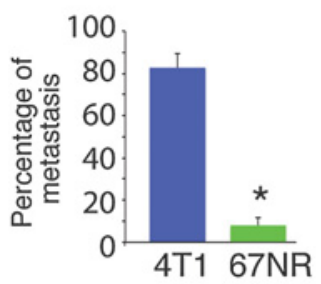

M

67NR

N

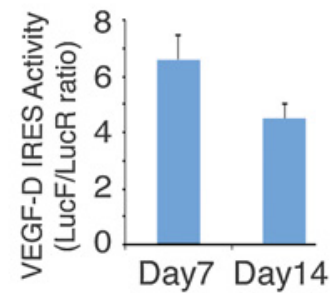

67NR

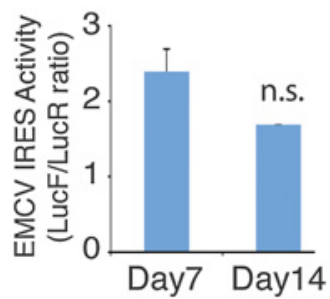

Figure 3.

Tumor posttranscriptional induction of VEGF-D in vivo promotes lymphatic vessel dilatation. A, quantitative RT-PCR in 4T1 and 67NR mice breast cancer cell lines. B, immunoblot analysis of VEGF-D in 4T1 and 67NR cell lines. C, quantification of VEGF-D relative levels $\left({ }^{*}, P<0.001\right)$. D, 4T1 and 67 NR tumor growth analysis. $\mathbf{E}$ and $\mathbf{F}$, staining for Lyve-1 (green) and DAPI (blue) demonstrated VEGF-D-independent lymphangiogenesis during breast carcinoma development $(*, P<0.001)$ Scale bar, $50 \mu \mathrm{m}$. G and $\mathbf{H}$, staining for -1 (green) and DAPI (blue) demonstrated a significant decrease of lymphatic vessel dilatation in tumor lacking VEGF-D $\left({ }^{*}, P<0.001\right)$. Scale bar, $25 \mu \mathrm{m}$. I and J, staining for -1 (green), cytokeratin (red), and DAPI (blue) demonstrated a significant decrease in lymph node metastasis $\left({ }^{*}, P<0.001\right)$. Scale bar, $50 \mu \mathrm{m}$. K-N, in vivo VEGF-D IRES activity exhibits a significant increase in $4 \mathrm{T1}$ (K) compared with EMCV (L), whereas no activity was promoted in 67 NR for both IRESs ( $\mathbf{M}$ and $\mathbf{N}$ ). n.s., nonsignificant. 
A

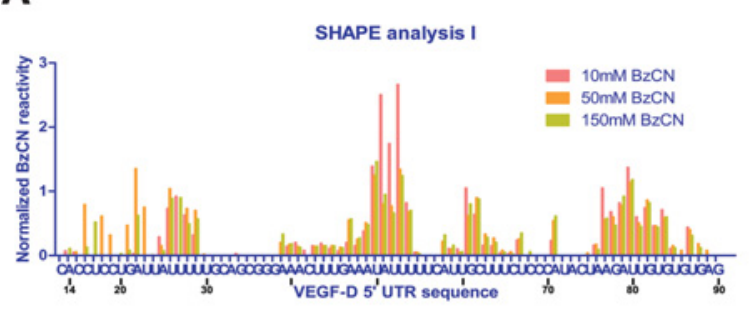

SHAPE analysis II

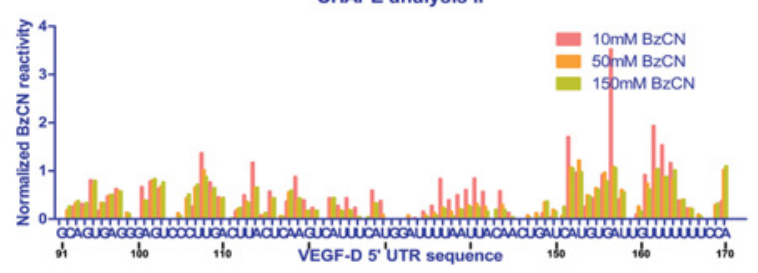

SHAPE analysis III

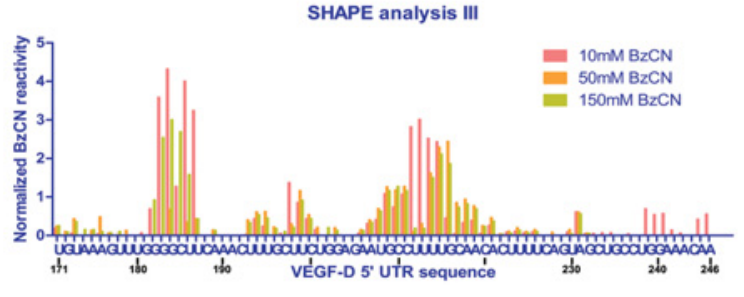

D

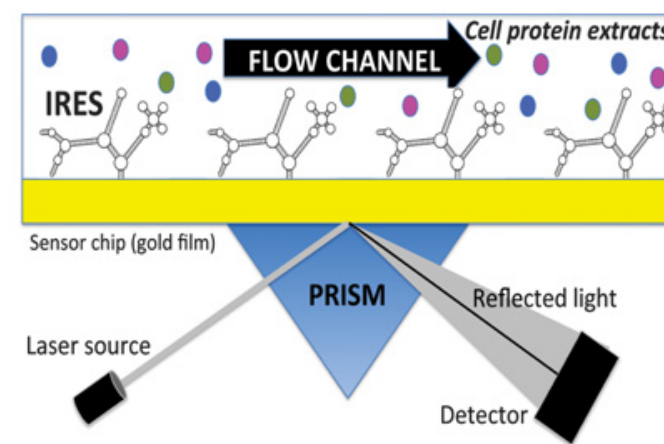

$\mathbf{F}$

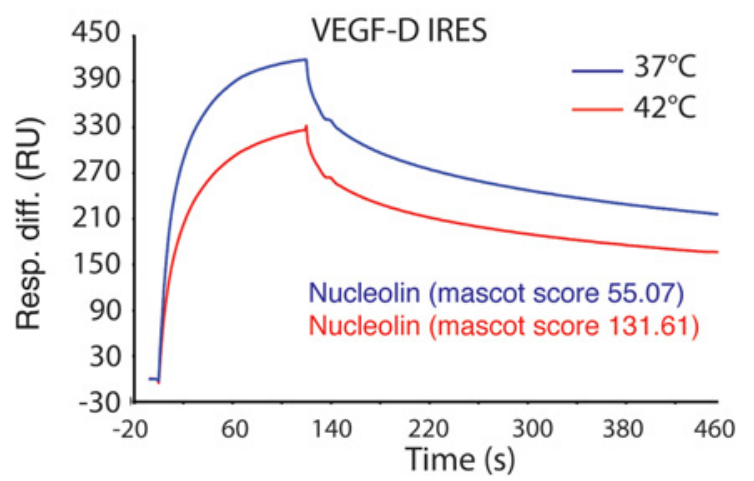

B
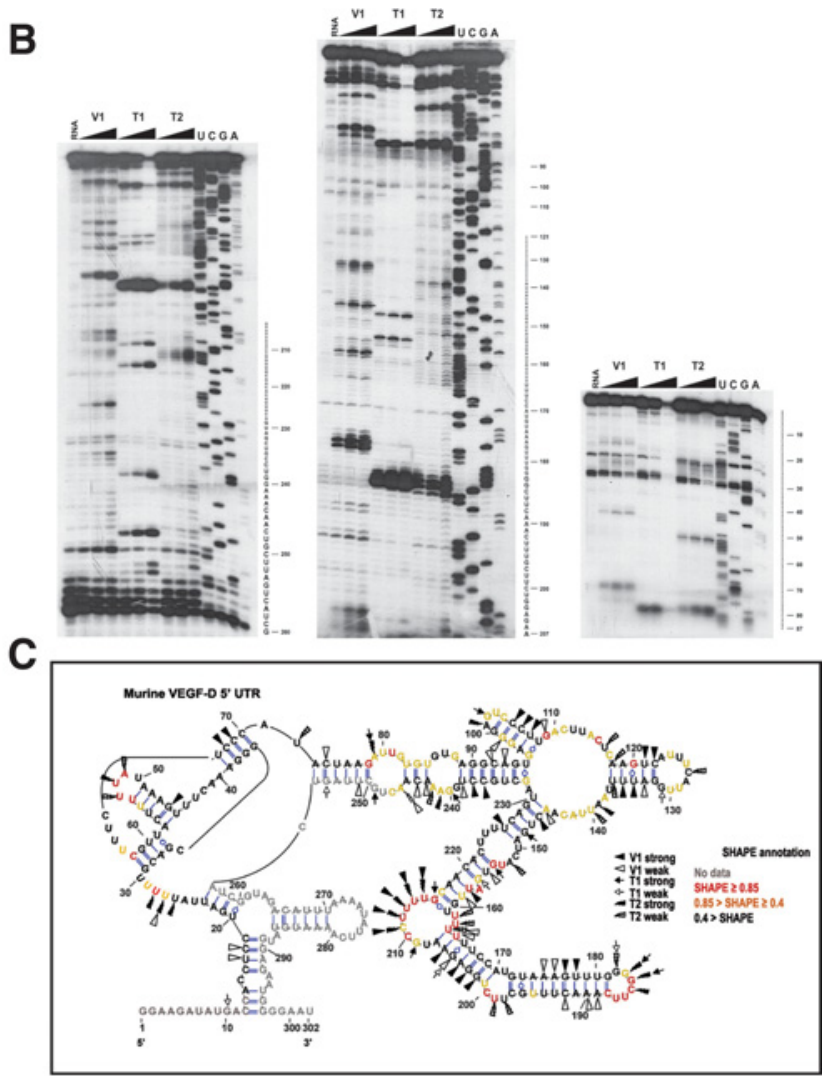

E

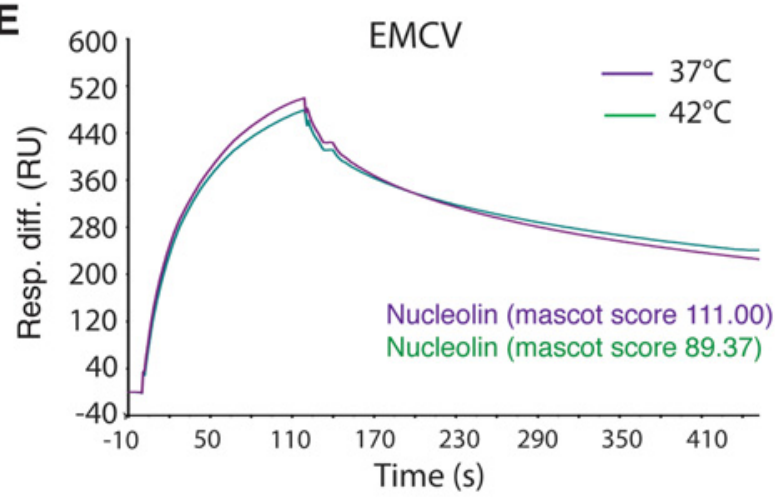


These data demonstrate that the VEGF-D mRNA contains an IRES that is activated during tumor growth in correlation with the high levels of VEGF-D protein expression.

Altogether, our data suggest a cap-independent regulation of VEGF-D translation that is not related with lymphangiogenesis, but directly correlated with lymphatic vessels dilatation and metastasis formation.

\section{VEGF-D IRES exhibits two alternative structures stabilized by an} ITAF: nucleolin

RNA structure plays important roles in every level of gene regulation including translation initiation. Predicting how mRNA 5'UTRs fold into secondary structures is an essential step in understanding the IRES activity. We then performed the shape analysis method for probing of VEGF-D mRNA $5^{\prime}$ UTR structure (Fig. 4A-C and Supplementary Fig. S5). The pattern of benzoyl-cyanide modifications suggested that VEGF-D 5' UTR is highly structured. Our structure prediction revealed the presence of a pseudoknot (nucleotides 30-70) and several stable helices. Nevertheless, enzymatic probing data (Fig. 4A and Supplementary Fig. S5) showed a region (nucleotides 225229) with double reactivity toward both double strand (V1) and single-strand probes (T2), and a native gel analysis confirmed the presence of two alternative structures (Fig. 4B). On the basis of shape analysis, we identified a predictive folding of VEGF-D IRES as shown in Fig. 4C.

The presence of alternative conformations at equilibrium has been previously observed also for the VEGF-C IRES (5) and could be an indication that the active structure might necessitate a cofactor (18), that is, an ITAF or a specific eIF, to fold correctly.

IRES activation requires binding of canonical initiation factors to initiate translation, but also other proteins called IRES transacting factors (ITAF) that facilitate ribosome recruitment to the IRES (32). ITAFs are RNA-binding proteins involved in other aspects of RNA metabolism that are important in carcinogenesis such as mRNA splicing, export and stability, and represent potential targeted therapy in certain types of cancer.

To identify VEGF-D ITAFs, we used an analytic method coupling surface plasmon resonance and mass spectrometry (BIA-MS; Fig. 4D-G), a technology recently validated for ITAF identification (33). Biotinylated VEGF-D and EMCV IRES RNAs were immobilized on a BIACORE streptavidin sensorchip (Fig. $4 \mathrm{D})$. Control $\left(37^{\circ} \mathrm{C}\right)$ or heat shock $\left(42^{\circ} \mathrm{C}\right)$ total cell protein extracts were injected into the BIACORE T200 apparatus to obtain the association phase (Fig. 4E and F). Bound proteins were recovered and identified by nano-LC/MS-MS after tryptic digestion. Interestingly, proteins bound the VEGF-D IRES with a lower affinity at $42^{\circ} \mathrm{C}$ compared with $37^{\circ} \mathrm{C}$, whereas no difference was observed for EMCV IRES (Fig. 4E and F). Mass spectrometry analysis allowed identification of a few proteins bound to the VEGF-D IRES, including an RNA-binding protein, nucleolin (Fig. 4E and F and Supplementary Fig. S5). As nucleolin has previously been described to be an ITAF for viral IRESs $(20,21)$, and plays a role in RNA stability of cellular oncogenes such as $\mathrm{Bcl} 2$ (34), we investigated its effect on VEGFD IRES activity.

Nucleolin ITAF activity is mediated by its subcellular location

To study whether nucleolin participates in VEGF-D translational initiation during heat shock stress, we first analyzed protein expression in breast cancer cell lines (Fig. 5). Surprisingly, no difference in nucleolin protein synthesis was observed in cells submitted to an increased temperature $\left(42^{\circ} \mathrm{C}\right.$; Fig. $\left.5 \mathrm{~A}\right)$. Interestingly, we found a delocalization of nucleolin from the nucleus to the cell cytoplasm under heat shock (Fig. 5B and $\mathrm{C}$ ). The protein export is in accordance with previous studies showing that ITAF activity depends on its subcellular location (19).

To determine the role of nucleolin in VEGF-D IRES activity under heat shock stress, we designed siRNAs against nucleolin (Fig. 5D-J). Nucleolin protein synthesis is inhibited by siRNA, but is not affected by control si scramble (Fig. 5D and E). To decipher whether the nucleolin knock down could modulate VEGFD synthesis, the VEGFD mRNA relative level and protein expression were analyzed under heat shock condition after knocking down the nucleolin. Despite a downregulation of mRNA level, VEGF-D protein level is maintained, suggesting a posttranscriptional regulation (Fig. $5 \mathrm{~F}$ and G). In that context, the knockdown of nucleolin induces a downregulation of protein expression confirming its role as an ITAF (Fig. 5G). To investigate the effect of nucleolin on VEGF-D translation, polysome profiling has been performed comparing VEGF-D expression under stressed condition in polysomal fraction from cells transfected with nucleolin siRNA (Supplementary Fig. $\mathrm{S} 6$ and Fig. 5H). We observed a strong downregulation of translated VEGFD in the absence of nucleolin at $42^{\circ} \mathrm{C}$ compared with $37^{\circ} \mathrm{C}$, suggesting that the downregulation of the ITAF directly affects the association of the mRNA with the polysomes (Fig. $5 \mathrm{H}$ ). As expected, in the absence of nucleolin, VEGF-D IRES activity was strongly decreased, whereas no effect was observed for EMCV IRES activity (Fig. 5I). In this context, VEGF-D IRES was affected by nucleolin knockdown, demonstrating the role of nucleolin as an ITAF under heat stress condition. To decipher whether transcription and cap-dependent translation is regulated by heat shock stress, we performed transcription and translation analysis on a gene involved in vascular biology that does not contain an IRES: platelet growth factor 4 (PF4). We show that PF4 is not regulated at the transcriptional level under heat shock condition (Supplementary Fig. S6). As expected, we observed a downregulation of PF4 mRNA under stressed condition in polysomal fraction (Supplementary Fig. S6).

\section{Figure 4.}

VEGF-D 5'UTR exhibits the presence of highly stable structures compatible with an IRES-driven mechanism of translation. A, quantification and normalization of the SHAPE analysis obtained by the QUSHAPE software. The 302 nucleotides long sequence of VEGF-D 5'UTR has been split into three graphs representing the $5^{\prime}$ (graph I, top), graph II (middle), and $3^{\prime}$ (graph III, bottom) regions. B, autoradiograms of RNA enzymatic probing experiments followed by primer extension showing the localization of the enzymatic cleavages obtained with RNase V1 (V1), RNase T1 (T1), and RNase T2 (T2). (i) RNA, control RNA without enzymes; (ii) V1, T1 and T2: three different increasing concentrations of the three RNAses; (iii) RNA sequencing ladders were run in parallel (U,C,G,A lanes on each gel). C, putative secondary structure of the murine $5^{\prime}$ UTR of VEGF-D mRNA. D, schematic representation of the BIACORE T200 analysis using surface plasmon resonance. $\mathbf{E}$ and $\mathbf{F}$, sensogram analysis for EMCV IRES (E) and VEGF-D IRES (F) coupled to mass spectrometry reveals the binding of a nuclear protein: nucleolin. 
A

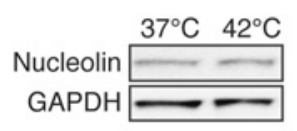

B

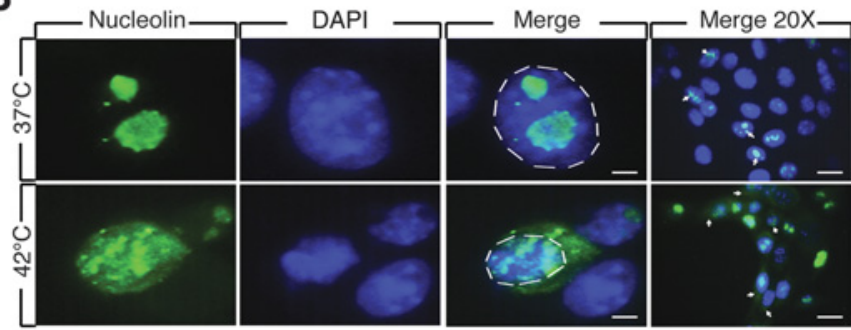

D

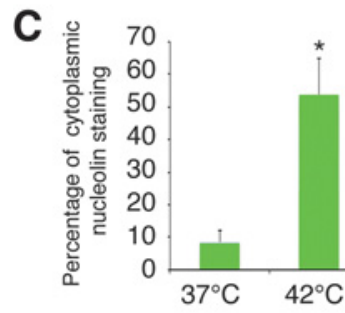

$\mathbf{F}$

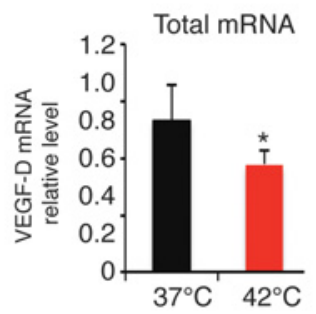

I

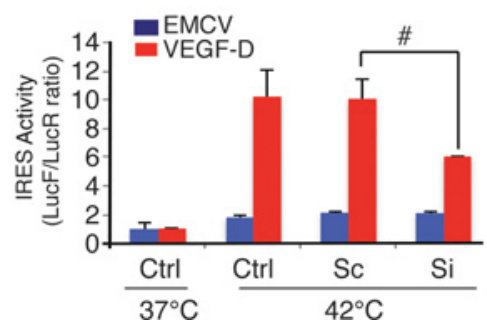

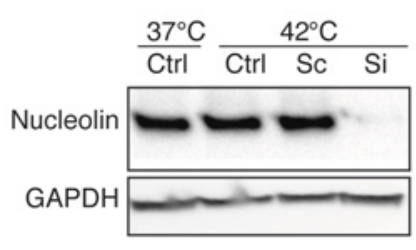

G

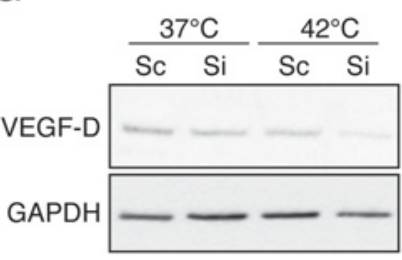

J

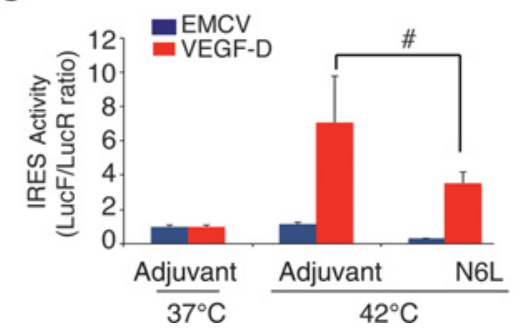

Figure 5.

VEGF-D IRES activity is regulated by nucleolin. A, immunoblot of nucleolin in mouse cell lines. B, staining for nucleolin (green) and DAPI (blue) in 4T1 submitted to heat shock; scale bar, $5 \mu \mathrm{m}$ (left); scale bar, $25 \mu \mathrm{m}$ (right). C, quantification of the percentage of $4 \mathrm{~T} 1$ cell lines, which exhibits a cytoplasm staining of nucleolin under increased temperature $\left.{ }^{*}, P<0.001\right)$. D, immunoblot of nucleolin in lysates of $4 \mathrm{T1}$ cells incubated in physiologic $\left(37^{\circ} \mathrm{C}\right)$ or heated $\left(42^{\circ} \mathrm{C}\right)$ temperature and treated with or without siRNA against nucleolin (Si) or a scrambled (Sc) siRNA control.

$\mathbf{E}$, densitometric quantification of the immunoblot $(\#, P<0.05) . \mathbf{F}$, quantitative VEGF-D RT-PCR on total mRNA from 4T1 cells incubated in physiologic $\left(37^{\circ} \mathrm{C}\right)$ or heated $\left(42^{\circ} \mathrm{C}\right)$ temperature. $\mathbf{G}$, immunoblot of VEGF-D in lysates of 4T1 cells incubated in physiologic $\left(37^{\circ} \mathrm{C}\right)$ or heated $\left(42^{\circ} \mathrm{C}\right)$ temperature and treated with or without siRNA against nucleolin (Si) or a scrambled (Sc) siRNA control. $\mathbf{H}$, comparison of VEGF-D mRNA relative levels in polysomal mRNA from 4T1 cells incubated in physiologic $\left(37^{\circ} \mathrm{C}\right)$ or heated $\left(42^{\circ} \mathrm{C}\right)$ temperature and treated with or without siRNA against nucleolin (Si) or a scrambled (Sc) siRNA control $\left(^{*}, P<\right.$ 0.01). I, VEGF-D IRES activity in 4 T1 cells incubated in physiologic $\left(37^{\circ} \mathrm{C}\right)$ or heated $\left(42^{\circ} \mathrm{C}\right)$ temperature and treated with or without siRNA against nucleolin (Si) or a scrambled (Sc) siRNA control (\#, $P<0.05)$. J, VEGF-D IRES activity in $4 \mathrm{T1}$ cells incubated in physiologic $\left(37^{\circ} \mathrm{C}\right)$ or heated $\left(42^{\circ} \mathrm{C}\right)$ temperature and treated with adjuvant (mannitol) or nucleolin inhibitor (N6L; \#, $P<0.05$ ).
To confirm the effect of nucleolin, we then used a pharmacologic inhibitor, a synthetic ligand of nucleolin: N6L (23). As expected, we observed a decrease of VEGF-D IRES activity in the presence of nucleolin inhibitor (Fig. 5J).

COX-2 inhibitors abolish VEGF-D stress response by modulating nucleolin expression

Recent studies have demonstrated that VEGF-D regulates the tumor-draining collecting lymphatic vessels dilatation through a prostaglandin (PG)-dependent mechanism, consistent with the elevated levels of inflammatory mediators, such as PGs $(28,35)$. VEGF-D modulates COX-2-derived PGE2 to promote tumor progression and metastasis leading to a chemoprotective effect of COX-2 inhibitors (NSAIDs) by reducing PGE2 levels. To determine the role of COX-2 inhibitors on molecular regulations of VEGF-D expression, we evaluated the effect of sc236 in vitro (Fig. 6A-E). As shown in Fig. 5, the increased temperature has no effect on nucleolin synthesis (Fig. 6A). Surprisingly, we observed a COX-2 inhibitor downregulation of nucleolin synthesis at both $37^{\circ} \mathrm{C}$ and $42^{\circ} \mathrm{C}$ (Fig.
6A), suggesting that the drug interferes with VEGF-D translational initiation by modulating its ITAF synthesis. Using immunocytodetection, we found that cytoplasmic nucleolin was hardly detected upon sc236 treatment in $4 \mathrm{~T} 1$ cell lines under heat shock conditions (Fig. 6B and C). In parallel, COX-2 inhibitor abolished heat shock-induced VEGF-D IRES activity in $4 \mathrm{~T} 1$ cells (Fig. 6D), but had no effect on 67NR cell lines (Fig. 6E). To investigate whether COX-2 inhibitor could modulate VEGF-D translation initiation in vivo, tumorbearing mice were treated every 2 days during 10 days by intraperitoneal injection of COX-2 inhibitor (Fig. 6F-J). As expected, we found a downregulation of nucleolin expression in tumors (Fig. 6F). IRES activities were studied in vivo at day 7 (1-2 mm diameter, well vascularized, nonmetastatic) and day 14 (4-8 $\mathrm{mm}$ diameter, necrotic, metastatic) to compare low-stressed to high-stressed condition (Fig. 6G). As expected, the EMCV viral IRES is not affected by the COX-2 inhibition. The VEGF-D IRES is activated at day 14, and this effect is abolished by COX-2 inhibitor (Fig. 6G), whereas no difference was observed in tumor growth (Supplementary 


\section{Figure 6.}

VEGF-D IRES activity is modulated by COX-2 inhibitor. A, quantification of nucleolin-positive pixels in $4 \mathrm{T1}$ cells submitted to heat shock $\left({ }^{*}, P<0.01\right)$. B, staining for nucleolin (green) and (blue) in heated $4 \mathrm{T1}$ cell lines incubated with COX-2 inhibitor (sc236). C,

quantification of the percentage of $4 \mathrm{~T}$ cell lines incubated with sc236, which exhibit a cytoplasm staining of nucleolin under increased temperature $\left({ }^{*}, P<0.001\right)$. D, stimulation of VEGF-D and EMCV IRES activity in 4T1 cell line $(\#, P<0.05)$. E, stimulation of VEGF-D and EMCV IRES activity in 67NR cell line $(\#, P<0.05)$. F, immunoblot of nucleolin in 4T1-bearing mice treated with mouse sc236. G, stimulation of 4T1 VEGF-D IRES activity in vivo is inhibited by sc236. $\mathbf{H}$, staining for LYVE-1 (green) and (blue) demonstrated a significant decrease of lymphatic vessel dilatation in sc236-treated 4T1 tumors. I, quantification of lymphatic vessel diameters in vivo in sc236-treated $4 \mathrm{T1}$ tumors $\left({ }^{*}, P<0.01\right)$. J, Evans blue perfusion of the $4 \mathrm{~T} 1 \mathrm{draining}$ lymphatics exhibits a vessel dilatation that is abolished after sc236 treatment. n.s., nonsignificant.
A
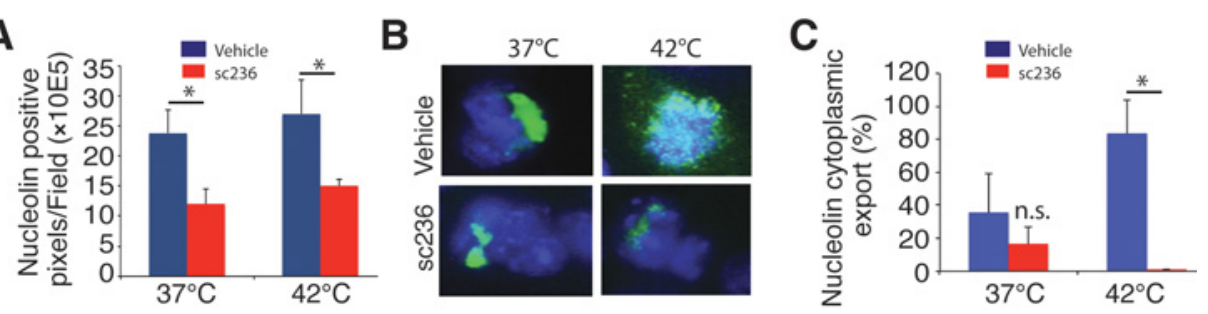

D

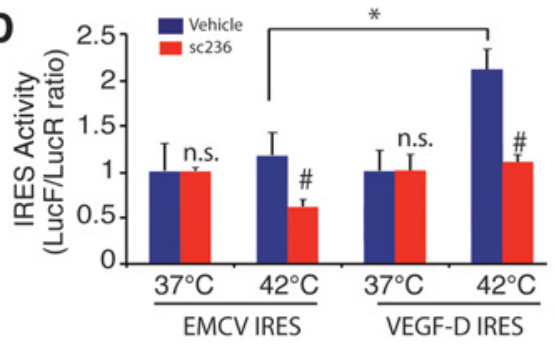

E $\left.{ }^{2.5}\right]$ 量 $\begin{gathered}\text { vehice } \\ \text { sc236 }\end{gathered}$

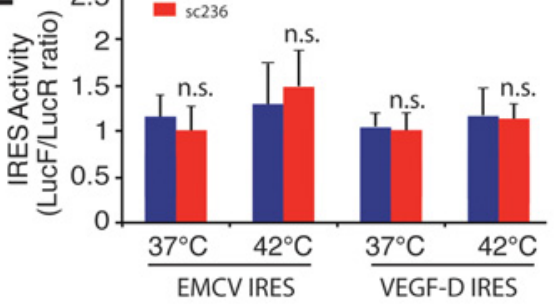

$\mathbf{F}$

G

H
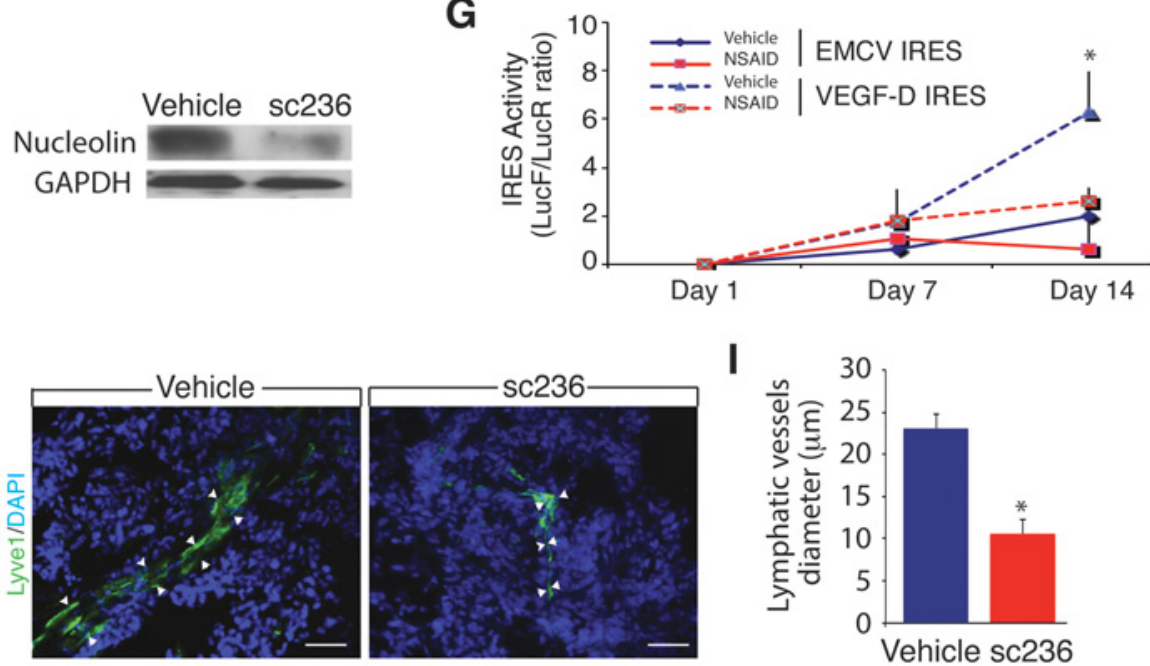

I

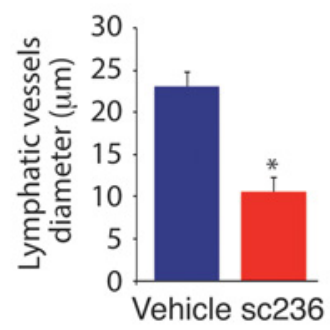

$\mathbf{J}$

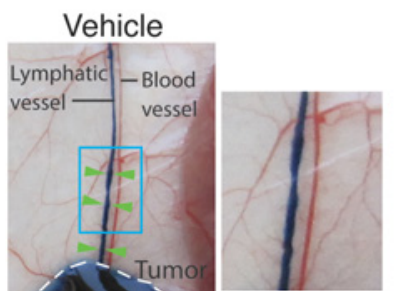

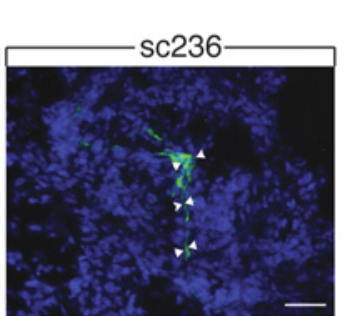

$\operatorname{sc236}$

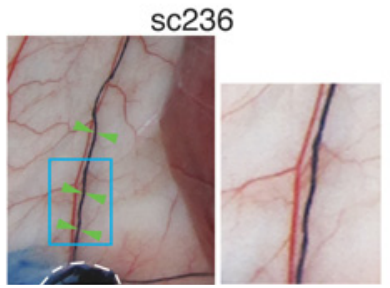

Fig. S7). In parallel, we observed a strong decrease of lymphatic vessel diameter in tumors (Fig. $6 \mathrm{H}$ and I) associated with a vasoconstriction of the tumor-draining collecting vessels in COX-2 inhibitor-treated mice (Fig. 6J). These data demonstrated for the first time that an anti-inflammatory drug can modulate growth factor synthesis under stress condition by controlling an ITAF subcellular location and synthesis.

\section{Discussion}

Tumor metastases are a leading cause of cancer-related mortality and can be promoted by both intrinsic and extrinsic factors in tumor cells. This study has identified an original translational regulation mechanism of VEGF-D expression under stress conditions in primary tumors promoting lymphatic vessel increased diameter that can be reversed by NSAIDs acting on ITAF expression. Translational initiation is promoted by eIF4E initiation factor binding to the mRNA. Under stress condition, eIF4E is targeted by the translational inhibitor 4EBinding Protein 1 (4E-BP1) in its hypophosphorylated form, which leads to inhibition of cap-dependent, but not cap-independent, translation (36). Also, translation reprograming was previously reported in inflammatory breast cancer due to an overexpression of eIF4GI and overexpression/dephosphorylation of 4E-BP1 $(37,38)$. 
We found a colocalization of these two markers with VEGF$\mathrm{D}$ in human breast carcinoma, suggesting a cap-independent translation initiation of VEGF-D mRNA. Moreover, we show that VEGF-D transcript levels are reduced in mice tumors, whereas VEGF-D protein levels are increased due to a switch from cap-dependent to IRES-dependent VEGF-D translation. Notably, this regulation seems to depend on an increased temperature, but is not regulated by hypoxia as it has been previously described for other (lymph)angiogenic growth factors, such as VEGF-A and VEGF-C, two related and homologous members of the VEGF family (5). This feature distinguishes VEGF-D from the other hypoxia-induced (lymph) angiogenic growth factors. Importantly, we found two alternative structures for VEGF-D 5'UTR, suggesting an equilibrium between basal and stressed conditions to facilitate the ITAF binding. Switching from cap-dependent to IRES-dependent translation of VEGF-D in tumor cells required adapter protein called ITAFs. The VEGF-D IRES might be regulated by distinct ITAFs, which would be activated during heat shock (and in inflammation), but not during hypoxia. Our findings reveal that nucleolin, a nucleolar protein involved in the control of transcription of ribosomal RNA, is translocated to the cytoplasm in response to heat shock and controls VEGF-D mRNA translation after binding to the IRES region. Nucleolin has been previously described as an ITAF for virus IRESs such as poliovirus (20). Recently, it has been found to enhance cellular IRES-dependent translation of specificity protein-1 (Sp1), a transcription factor involved in tumor cells proliferation $(22,39)$. These results are in accordance with findings showing that IRES-dependent translation initiation is regulated by ITAF's subcellular location (19).

Tumor cells spread to distant organs via lymphatic using two mechanisms: lymphangiogenesis and lymphatic dilatation. Here, we demonstrated that breast tumors lacking VEGF-D expression do not exhibit a defect in primary tumor or lymph nodes lymphangiogenesis, but have a reduced amount of dilated lymphatic vessels associated with an inhibition of metastasis. Our findings suggested that this process is restricted to breast cancer, in agreement with previous studies showing a correlation between metastases and dilated lymphatic vessels in breast cancer patients (40).

We know for decades that inflammation is a major inducer of prostaglandin-induced vasodilatation (29). Previous studies reported that expression of VEGF-D by cancer cells promoted tumor lymphatic vessels dilatation and metastasis by regulating prostaglandins produced by the collecting lymphatic endothelium (1). COX-2 inhibitors, the most common NSAIDs, reduce VEGF-D-driven metastasis by reversing the morphologic changes in collecting lymphatic vessels. In this study, we demonstrated that COX-2 inhibitor-induced lymphatic vessel constriction is in part due to a downregulation of VEGF-D IRES translation initiation. We observed that the VEGF-D IRES activity is abolished by NSAIDs during tumor development. Notably, vessel diameters were reduced in COX-2 inhibitortreated mice. These data indicate that lymphatic vessels plasticity is controlled by a regulatory loop involving VEGF-D

\section{References}

1. Karnezis T, Shayan R, Caesar C, Roufail S, Harris NC, Ardipradja K, et al. VEGF-D promotes tumor metastasis by regulating prostaglandins pro- protein synthesis and prostaglandin signaling (Supplementary Fig. S8).

Our study may be relevant to provide the first evidence of a translational initiation control of the lymphatic vessels dilatation, a major pathophysiologic event in tumor metastasis.

A key finding of our study is that increased temperature mediates lymphangiogenic growth factor responses, through the suppression of cap-dependent and an increase of IRESmediated mRNA translation. Collectively, our data allow us to propose the existence of two VEGF-D translational control pathways involved in cancer dissemination that depends on stresses associated with inflammation. A nucleolar protein, the nucleolin, which can provide a novel therapeutic target for lymphatic vessel plasticity during tumor inflammation, controls this mechanism.

\section{Disclosure of Potential Conflicts of Interest}

No potential conflicts of interest were disclosed.

\section{Authors' Contributions}

Conception and design: F. Morfoisse, A. Adoue, S. Pyronnet, J. GuillermetGuibert, A.-C. Prats, B.H. Garmy-Susini

Development of methodology: F. Morfoisse, A. Adoue, F. Pujol, R.J. Schneider, A.-C. Prats, B.H. Garmy-Susini

Acquisition of data (provided animals, acquired and managed patients, provided facilities, etc.): F. Tatin, F. Hantelys, A. Adoue, A.-C. Helfer, S. Cassant-Sourdy, L. Ligat, F. Lopez, S. Marzi, B.H. Garmy-Susini

Analysis and interpretation of data (e.g., statistical analysis, biostatistics, computational analysis): F. Morfoisse, F. Tatin, A. Adoue, A.-C. Helfer, L. Ligat, F. Lopez, J. Guillermet-Guibert, S. Marzi, R.J. Schneider, A.-C. Prats, B.H. GarmySusini

Writing, review, and/or revision of the manuscript: S. Pyronnet, J. GuillermetGuibert, S. Marzi, R.J. Schneider, A.-C. Prats, B.H. Garmy-Susini

Administrative, technical, or material support (i.e., reporting or organizing data, constructing databases): F. Lopez, B.H. Garmy-Susini

Study supervision: F. Morfoisse, B.H. Garmy-Susini

Other (supplier of an antagonist of nucleolin): J. Courty

\section{Acknowledgments}

We thank J.J. Maoret for his technical support and Y. Barreira from the platform Anexplo Genotoul (Inserm US006, Toulouse, France) for their outstanding technical assistance, $\mathrm{M}$. Khatib from the imaging platform of I2MC for her scientific and technical support, and A. Henras (LBME-CNRS UMR 5100, Toulouse, France) for his scientific and technical support in ribosome profiling. We thank Dr. P. Romby (IBMC-CNRS) and D. Arvanitis for their scientific support.

\section{Grant Support}

This work has been supported by the Ligue Régionale Contre le Cancer, the foundation ARC pour la Recherche sur le Cancer, the foundation Lefoulon Delalande, Cancéropôle Grand Sud-Ouest GSO, IDEX Paul Sabatier Federal University, AFM-Telethon, Région Midi-Pyrénées.

The costs of publication of this article were defrayed in part by the payment of page charges. This article must therefore be hereby marked advertisement in accordance with 18 U.S.C. Section 1734 solely to indicate this fact.

Received November 23, 2015; revised May 11, 2016; accepted May 24, 2016; published OnlineFirst June 8, 2016 
2. Zheng W, Aspelund A, Alitalo K. Lymphangiogenic factors, mechanisms, and applications. J Clin Invest 2014;124:878-87.

3. Joukov V, Sorsa T, Kumar V, Jeltsch M, Claesson-Welsh L, Cao Y, et al. Proteolytic processing regulates receptor specificity and activity of VEGF-C. ЕMBO J 1997;16:3898-911.

4. Stacker SA, Stenvers K, Caesar C, Vitali A, Domagala T, Nice E, et al Biosynthesis of vascular endothelial growth factor-D involves proteolytic processing which generates non-covalent homodimers. J Biol Chem 1999;274:32127-36

5. Morfoisse F, Kuchnio A, Frainay C, Gomez-Brouchet A, Delisle MB, Marzi S, et al. Hypoxia induces VEGF-C expression in metastatic tumor cells via a HIF-1alpha-independent translation-mediated mechanism. Cell Rep 2014;6:155-67.

6. Lambrechts D, Carmeliet P. Genetics in zebrafish, mice, and humans to dissect congenital heart disease: insights in the role of VEGF. Curr Top Dev Biol 2004;62:189-224.

7. Hoier B, Hellsten Y. Exercise-induced capillary growth in human skeletal muscle and the dynamics of VEGF. Microcirculation 2014;21:301-14.

8. Stacker SA, Caesar C, Baldwin ME, Thornton GE, Williams RA, Prevo R, et al VEGF-D promotes the metastatic spread of tumor cells via the lymphatics. Nat Med 2001;7:186-91.

9. Stacker SA, Achen MG, Jussila L, Baldwin ME, Alitalo K. Lymphangiogenesis and cancer metastasis. Nat Rev Cancer 2002;2:573-83.

10. Kopfstein L, Veikkola T, Djonov VG, Baeriswyl V, Schomber T, Strittmatter $\mathrm{K}$, et al. Distinct roles of vascular endothelial growth factor-D in lymphangiogenesis and metastasis. Am J Pathol 2007;170:1348-61.

11. Girling JE, Donoghue JF, Lederman FL, Cann LM, Achen MG, Stacker SA, et al. Vascular endothelial growth factor-D over-expressing tumor cells induce differential effects on uterine vasculature in a mouse model of endometrial cancer. Reprod Biol Endocrinol 2010;8:84.

12. Paquet-Fifield S, Levy SM, Sato T, Shayan R, Karnezis T, Davydova N, et al. Vascular endothelial growth factor-d modulates caliber and function of initial lymphatics in the dermis. J Invest Dermatol 2013;133:2074-84

13. Sonenberg N, Hinnebusch AG. New modes of translational control in development, behavior, and disease. Mol Cell 2007;28:721-9.

14. Holcik M, Sonenberg N. Translational control in stress and apoptosis. Nat Rev Mol Cell Biol 2005;6:318-27.

15. Miller DL, Dibbens JA, Damert A, Risau W, Vadas MA, Goodall GJ. The vascular endothelial growth factor mRNA contains an internal ribosome entry site. FEBS Lett 1998;434:417-20.

16. Morfoisse F, Renaud E, Hantelys F, Prats AC, Garmy-Susini B [Lymphangiogenic gene expression adaptation in tumor hypoxic environment]. Med Sci 2014;30:506-8.

17. Lewis SM, Veyrier A, Hosszu Ungureanu N, Bonnal S, Vagner S, Holcik M. Subcellular relocalization of a trans-acting factor regulates XIAP IRESdependent translation. Mol Biol Cell 2007;18:1302-11.

18. Sonenberg N, Hinnebusch AG. Regulation of translation initiation in eukaryotes: mechanisms and biological targets. Cell 2009;136:731-45.

19. Lewis SM, Holcik M. For IRES trans-acting factors, it is all about location. Oncogene 2008;27:1033-5.

20. Izumi RE, Valdez B, Banerjee R, Srivastava M, Dasgupta A. Nucleolin stimulates viral internal ribosome entry site-mediated translation. Virus Res 2001;76:17-29.

21. Peddigari S, Li PW, Rabe JL, Martin SL. hnRNPL and nucleolin bind LINE-1 RNA and function as host factors to modulate retrotransposition. Nucleic Acids Res 2013;41:575-85.
22. Hung CY, Yang WB, Wang SA, Hsu TI, Chang WC, Hung JJ. Nucleolin enhances internal ribosomal entry site (IRES)-mediated translation of Sp1 in tumorigenesis. Biochim Biophys Acta 2014;1843:2843-54.

23. Destouches D, Page N, Hamma-Kourbali Y, Machi V, Chaloin O, Frechault $\mathrm{S}$, et al. A simple approach to cancer therapy afforded by multivalent pseudopeptides that target cell-surface nucleoproteins. Cancer Res 2011;71:3296-305.

24. Martineau Y, Le Bec C, Monbrun L, Allo V, Chiu IM, Danos O, et al. Internal ribosome entry site structural motifs conserved among mammalian fibroblast growth factor 1 alternatively spliced mRNAs. Mol Cell Biol 2004;24:7622-35.

25. Pestova TV, Kolupaeva VG, Lomakin IB, Pilipenko EV, Shatsky IN, Agol VI, et al. Molecular mechanisms of translation initiation in eukaryotes. Proc Natl Acad Sci U S A 2001;98:7029-36.

26. Sachs AB. Cell cycle-dependent translation initiation: IRES elements prevail. Cell 2000;101:243-5.

27. Vagner S, Galy B, Pyronnet S. Irresistible IRES. Attracting the translation machinery to internal ribosome entry sites. EMBO Rep 2001;2:893-8.

28. Karnezis T, Shayan R, Fox S, Achen MG, Stacker SA. The connection between lymphangiogenic signalling and prostaglandin biology: a missing link in the metastatic pathway. Oncotarget 2012;3:893-906.

29. Williams TJ, Peck MJ. Role of prostaglandin-mediated vasodilatation in inflammation. Nature 1977;270:530-2.

30. Banerii S, Ni J, Wang SX, Clasper S, Su J, Tammi R, et al. LYVE-1, a new homologue of the $\mathrm{CD} 44$ glycoprotein, is a lymph-specific receptor for hyaluronan. J Cell Biol 1999;144:789-801.

31. Breiteneder-Geleff S, Soleiman A, Horvat R, Amann G, Kowalski H, Kerjaschki D. [Podoplanin-a specific marker for lymphatic endothelium expressed in angiosarcoma]. Verh Dtsch Ges Pathol 1999;83:270-5.

32. Faye $\mathrm{MD}$, Holcik $\mathrm{M}$. The role of IRES trans-acting factors in carcinogenesis Biochim Biophys Acta 2015;1849:887-97.

33. Ainaoui N, Hantelys F, Renaud-Gabardos E, Bunel M, Lopez F, Pujol F, et al Promoter-dependent translation controlled by p54nrb and hnRNPM during myoblast differentiation. PLoS One 2015;10:e0136466.

34. Willimott S, Wagner SD. Post-transcriptional and post-translational regulation of Bcl2. Biochem Soc Trans 2010;38:1571-5.

35. Stacker SA, Williams SP, Karnezis T, Shayan R, Fox SB, Achen MG Lymphangiogenesis and lymphatic vessel remodelling in cancer. Nat Rev Cancer 2014;14:159-72.

36. Whalen SG, Gingras AC, Amankwa L, Mader S, Branton PE, Aebersold R, et al. Phosphorylation of eIF-4E on serine 209 by protein kinase C is inhibited by the translational repressors, $4 \mathrm{E}$-binding proteins. J Biol Chem 1996;271:11831-7.

37. Silvera D, Arju R, Darvishian F, Levine PH, Zolfaghari L, Goldberg I, et al Essential role for eIF4GI overexpression in the pathogenesis of inflammatory breast cancer. Nat Cell Biol 2009;11:903-8.

38. Avdulov S, Li S, Michalek V, Burrichter D, Peterson M, Perlman DM, et al Activation of translation complex eIF4F is essential for the genesis and maintenance of the malignant phenotype in human mammary epithelial cells. Cancer Cell 2004;5:553-63.

39. Luo J, Wang X, Xia Z, Yang L, Ding Z, Chen S, et al. Transcriptional factor specificity protein 1 (SP1) promotes the proliferation of glioma cells by upregulating midkine (MDK). Mol Biol Cell 2015;26:430-9.

40. Lu Q, Hua J, Kassir MM, Delproposto Z, Dai Y, Sun J, et al. Imaging lymphatic system in breast cancer patients with magnetic resonance lymphangiography. PLoS One 2013;8:e69701. 


\section{Cancer Research}

$A A C R$ R Amerian Association

The Journal of Cancer Research (1916-1930) | The American Journal of Cancer (1931-1940)

\section{Nucleolin Promotes Heat Shock-Associated Translation of VEGF-D to Promote Tumor Lymphangiogenesis}

Florent Morfoisse, Florence Tatin, Fransky Hantelys, et al.

Cancer Res 2016;76:4394-4405. Published OnlineFirst June 8, 2016.

\section{Updated version Access the most recent version of this article at:} doi:10.1158/0008-5472.CAN-15-3140

Supplementary Access the most recent supplemental material at:

Material http://cancerres.aacrjournals.org/content/suppl/2016/06/08/0008-5472.CAN-15-3140.DC1

Cited articles This article cites 40 articles, 12 of which you can access for free at: http://cancerres.aacrjournals.org/content/76/15/4394.full.html\#ref-list-1

E-mail alerts Sign up to receive free email-alerts related to this article or journal.

Reprints and To order reprints of this article or to subscribe to the journal, contact the AACR Publications Department at Subscriptions pubs@aacr.org.

Permissions To request permission to re-use all or part of this article, contact the AACR Publications Department at permissions@aacr.org. 